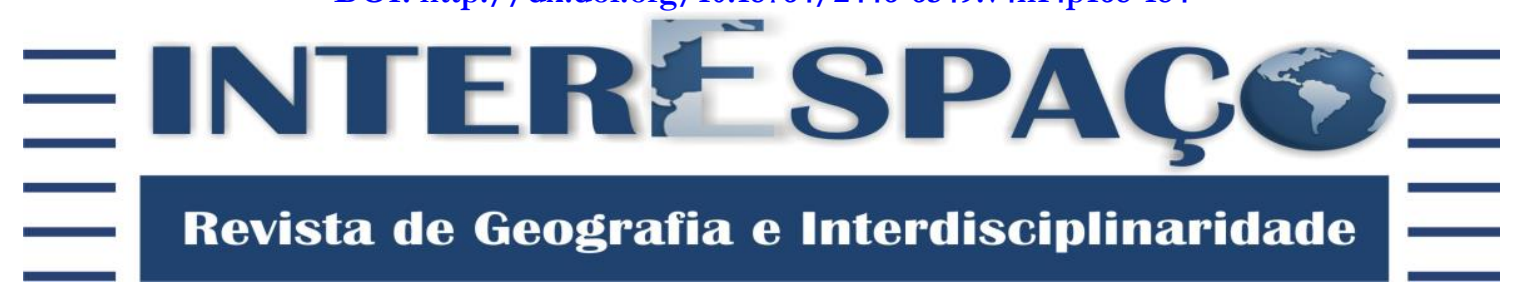

\title{
LUGAR E PATRIMÔNIO CULTURAL: a Praça das Bandeiras na área central da cidade de Araguaína-TO
}

\section{LUGAR AND CULTURAL HERITAGE: the Bandeiras Square in the central area of the city of Araguaína-TO}

\section{LUGAR Y EL PATRIMONIO CULTURAL: la Plaza de las Banderas en la zona céntrica de la ciudad de Araguaína-TO}

\section{Antônia Márcia Duarte Queiroz}

Doutora em Geografia pela Universidade Federal de Uberlândia - UFU. Professora do Curso de Geografia da Universidade Federal do Tocantins - UFT/Campus de Araguaína. amdq@uft.edu.br

\section{Roberto Antero da Silva}

Doutor em Geografia pela Universidade Estadual do Ceará - UECE. Professor do Curso de Geografia da Universidade Federal do Tocantins - UFT/Campus de Araguaína. robertoantero@uft.edu.br

Recebido para avaliação em 10/06/2018; Aceito para publicação em 20/08/2018.

\section{RESUMO}

Este artigo objetiva discutir sobre a área central da cidade de Araguaína (TO) à luz da Geografia. O foco teórico se volta para a categoria "lugar" e patrimônio cultural, tendo como objeto de estudo a Praça das Bandeiras localizada no centro da cidade. A análise utiliza-se dos resultados do projeto de extensão "Nós Propomos", desenvolvido em parceria entre as Universidades Instituto de Geografia e Ordenamento do Território da Universidade de Lisboa (IGOT/UL) e Universidade Federal do Tocantins (UFT). A metodologia qualitativa serviu de norteamento, pois se utilizou de pesquisa de campo, para observação, entrevistas e aquisição de imagens. Portanto, a leitura da praça à luz da Geografia produz reflexões sobre a importância da Praça das Bandeiras, como patrimônio cultural na área central da cidade, e sublinham que as praças contribuem na construção dos lugares centrais urbanos na formação da cidade. Essa construção se produz das relações que são formas expressas da interação, tanto de ordem social, como econômica, política e cultural.

Palavras-chave: Espaço Urbano; Lugar Central; Praça da Bandeira; Patrimônio.

\section{ABSTRACT}

This article aims to discuss the central area of the city of Araguaina (TO) in the light of the Geography. Theoretical focus turns back to the category "place" and cultural heritage having as object of study the flags square in the city centre. The analysis uses the results from extension project "Nós Propomos", developed in partnership between universities Instituto de Geografia e Ordenamento do Território da Universidade de Lisboa (IGOT/UL) and Universidade Federal do Tocantins (UFT). The qualitative methodology served as guidance, as field research was used for observation, interviews and image acquisition. Therefore, the reading of the square in light of geography produces reflections on the importance of the Plaza of the flags as cultural heritage in central area of the city, this stress that the squares contribute in the construction of the central urban places in the formation of the city. This construction produces the relations which are ways expressed the interaction of social, economic, political and cultural. 
|Antônia Márcia Duarte Queiroz|

Keywords: Urban Space; Central Place; Bandeira Square; Heritage.

\section{RESUMEN}

Este artículo pretende discutir la zona central de la ciudad de Araguaína (TO) a la luz de la Geografía. Enfoque teórico se vuelve a la categoría "lugar" y patrimonio cultural, teniendo como objeto de estudio la Plaza de las Banderas en el centro de la ciudad. El análisis utiliza los resultados del proyecto de extensión "Nós Propomos", desarrollado en colaboración entre las universidades Instituto de Geografia e Ordenamento do Território da Universidade de Lisboa (IGOT/UL) y Universidade Federal do Tocantins (UFT). La metodología cualitativa sirve como dirección, como investigación de campo se utilizó para la observación, entrevistas y adquisición de la imagen. Por lo tanto, la lectura de la plaza a la luz de geografía produce reflexiones sobre la importancia de la Plaza de las Banderas como patrimonio cultural en la zona central del estrés de la ciudad que los cuadrados, el contribuyen en la construcción de los lugares centrales urbanos en el formación de la ciudad. Esta construcción produce las relaciones que se formas expresa la interacción social, económica, política y cultural.

Palabras clave: Espacio Urbano; Lugar Central; Plaza de la Bandera; Patrimonio.

\section{INTRODUÇÃO}

A Geografia reflete sobre significados de espaços e lugares e revela que o espaço representa um recurso humano que constitui um local de confronto, por parte dos atores sociais, que comporta a marca e interferência da ação humana. Nas concepções sobre o lugar, a Geografia se interessa pelas concepções de representação por meio de processos e acumulações históricas.

O surgimento da área central foi percebido de forma nítida com a Revolução Industrial. $\mathrm{O}$ grande aumento de produtos industrializados gerou a necessidade de uma malha de transportes que suprisse a crescente demanda, dando ensejo à construção das grandes ferrovias.

A partir de então se verifica um processo de aglutinação em torno das estações ferroviárias, pelo grande fluxo de pessoas que nelas circulavam. Os empresários buscavam se estabelecer próximos às massas de pretensos consumidores. Com isso, iniciou-se a aglutinação de investimentos e estabelecimentos em torno destas estações de transportes, delimitando a área central da cidade.

Dentre os setores que compõem o espaço urbano, a área central possui significativa magnitude enquanto forma espacial. Localizada, geralmente na parte mais antiga da cidade, ela é facilmente reconhecida no tecido urbano por uma série de fatores, dos quais se destacam a sua complexidade funcional devido à alta diversidade na concentração de comércio e serviços, a sua acessibilidade, no sentido de que é foco da cidade e da hinterlândia, o alto grau de reestruturação arquitetônica e econômica, cujos fatores são responsáveis por sua valorização, e imponente verticalização. 
|Lugar e patrimônio cultural: a Praça das Bandeiras na área central da cidade de Araguaína-TO|

|Antônia Márcia Duarte Queiroz|

Não obstante, sobre a importância do centro da cidade enquanto elemento fundamental da estrutura urbana destaca-se que a conceptualização e a identificação desse sítio e de suas diferentes setorizações ainda apresentam-se envoltos em uma nebulosa.

Comumentemente verifica-se uma variedade de expressões atribuídas ao centro urbano, como centro principal, centro histórico, hipercentro, algumas utilizadas de forma equivocada. O núcleo central caracteriza-se como o ponto de concentração máxima das atividades de comércio e serviços e, por conseguinte, de infraestruturas, em especial as de comunicação. Por isso, "constitui o ponto onde os preços do solo atingem os valores mais altos, bem como objeto de interesse de diversos atores sociais, o que direta ou indiretamente contribui para a manutenção da supremacia dessa área” (ALVES, 2011, p. 62).

Segundo Vaz (2006), um lugar não constitui um mero contentor ou um simples ponto no espaço, mas representa um local de encontro, que possibilita aos atores sociais diversos contextos de transação e modos de coexistências e de conflitos. Isto significa que o lugar detém, além de contornos físicos, uma dimensão de copresença humana, ou seja, uma significação simbólica.

As praças, enquanto patrimônios identificam-se nas palavras de Drummond (2007), as quais apontam que o urbano é a capital do patrimônio, e se distingue em patrimônio cultural construído pelos humanos e o natural construído maciçamente por processos supra-humanos ou extra-humanos.

Nesse contexto, discutiu-se a importância da Praça das Bandeiras localizada na área central da cidade de Araguaína - TO. Por intermédio de análises das concepções de lugar e patrimônio cultural reconhece nas praças um conjunto de formas naturais e artificiais de objetos que têm idades diferentes, possuidoras de uma herança de diferentes momentos, ou seja, um espaço em constante movimentação.

Na primeira parte refletimos sobre a área central no contexto da Geografia Urbana, suas significações simbólicas e culturais na formação da cidade. A segunda se refere à questão urbana sob o enfoque geográfico na formação da cidade de Araguaína e sua importância para o Norte do Tocantins. Por fim, a última reflexão reflete, à luz da Geografia e comunidade escolar regional, sobre a importância das praças na área central dessa cidade na perspectiva do lugar de patrimônio cultural.

\section{AS PRAÇAS DOS CENTROS URBANOS: patrimônio cultural a partir da significação do lugar}


De acordo com Corrêa (1995), a área central constitui-se no foco principal não apenas da cidade, mas também de sua hinterlândia. Entre os setores que compõem o espaço urbano, a área central tem significativa magnitude como forma espacial. Localizada geralmente na parte mais antiga da cidade, ela é facilmente reconhecida no tecido urbano por uma série de fatores, entre os quais se destacam sua complexidade funcional em razão da alta diversidade na concentração de comércio e serviços, sua acessibilidade, no sentido de que é foco da cidade e da hinterlândia, e seu alto grau de reestruturação arquitetônica e econômica, cujos fatores são responsáveis por sua valorização e imponente verticalização.

As cidades são consideradas por Lopes (2012) como expressão material das relações sociais que nela ocorrem, não são formações recentes. Desde seu surgimento até a contemporaneidade, as cidades sofreram modificações consideráveis, tanto em suas formas como em suas funções, de acordo com os interesses da sociedade que ocupava o território e da maneira como ela se reproduzia no espaço.

[...] a partir do final do século XIX, com o adensamento populacional urbano e tendo em vista o desenvolvimento de atividades comerciais e a formação de uma "sociedade de consumo", o espaço urbano sofre intensas alterações em sua organização interna, especialmente a partir da aglomeração de atividades terciárias em uma área especifica da cidade. Essa concentração ocorre na chamada Área Central, local de mais fácil acesso dentro do espaço urbano, onde se concentram fluxos de pessoas, mercadorias, informações e meios de transporte (LOPES, 2012, p. 37).

A praça localizada na área central se insere nessa concentração de fluxos de serviços e pessoas, citadas por Lopes (2012). Lauande Junior (2008) acrescenta que muitas são as interpretações do que vem a ser uma praça como espaço urbano, tornando-se difícil encontrar entre os estudiosos uma mesma definição.

Lauande Junior (2008) admite que a praça deve ser entendida como qualquer categoria de espaço urbano: o resultado da interação de vários aspectos que emprestam características próprias a um determinado sistema social-temporal que o produz. É possível afirmar que a cidade é uma expressão espacial da evolução social, pois é através dessa interação que a sociedade modifica a natureza com o intuito de atingir sua satisfação e suas necessidades sociais, econômicas e culturais.

Para Tuan (1983), existem vários tipos de espaços, que podem ser individuais ou grupais, onde são vividas as experiências do "outro". Considera ainda o espaço míticoconceitual, pois extrapola para além da evidência dos sentidos em direção a estruturas mais abstratas. Afirma que o lugar se constitui quando o espaço se torna familiar para a pessoa, o que denomina como espaço vivido da experiência. 
Tuan (1983) afirma que há alguns sentimentos e atitudes relacionados ao lugar, que podem ser: 1) topofilia, que se refere àquele que tem apego ao lugar, se sente seguro; 2) topofobia, que está relacionada àquele que apresenta aversão a algum lugar específico; 3) topocídio, que é a destruição do lugar; e 4) topo-reabilitação, que é a restauração, a recuperação do lugar.

Archela (2004) aponta que podemos compreender 'lugar' como algo inacabado e que está num processo de constante alteração, aberto e em movimento. Daí a necessidade de ampliar o entendimento do vivido para o concebido. Analisa as diferentes maneiras como as pessoas sentem e conhecem o espaço e o lugar.

Este se torna, então, um produto da experiência humana, da própria existência, do seu quotidiano, do envolvimento do indivíduo com o mundo, da necessidade de segurança e de sentir raízes, sociais e biológicas. É um espaço físico conotado socialmente com as relações sociais que se desenrolam.

Os argumentos supracitados serviram de embasamento teórico para a análise da área central e do lugar na perspectiva da cidade de Araguaína.

De acordo com Santos (2001), a palavra patrimônio está historicamente associada ou à noção do sagrado, ou à noção e herança, de memória do indivíduo, de bens de família. O interesse público impede legalmente que eles sejam destruídos ou mutilados. $\mathrm{O}$ ato do tombamento, prerrogativa do poder Executivo, não implica desapropriação e nem determina o uso, tratando-se, sim, de uma fórmula realista de compromisso entre o direito individual à propriedade e a defesa do interesse público relativamente à preservação de valores culturais.

Santos (2001) assevera que hoje um dos maiores desafios à gestão do patrimônio cultural é definir conceitual e legalmente novas formas de acautelamento compatíveis com sua abrangência cada vez maior e com o exercício dos direitos culturais do cidadão, reconhecidos no texto da Constituição de 1988, particularmente no artigo 215: “O Estado garantirá a todos o pleno exercício dos direitos culturais e acesso às fontes da cultura nacional [...]" e no artigo 216: “O Poder Público, com a colaboração da comunidade, promoverá e protegerá o patrimônio cultural brasileiro, por meio de inventários, registros, vigilância, tombamento e desapropriação, e de outras formas de acautelamento e preservação".

Santos (2001) adverte que, durante praticamente um século de trabalho e discussões no âmbito internacional e 64 anos no Brasil, o caráter simbólico do patrimônio vem sendo ampliado. A ideia de um patrimônio comum a um grupo social, definidor de sua identidade 
e como tal merecedor de proteção nasce no final do século XVIII, com a visão moderna de história e de cidade (BABELON; CHASTEL, 1994 apud SANTOS, 2001).

Para a autora supracitada, no Brasil, a promulgação do Decreto-Lei no 25, de 30 de novembro de 1937, organizou a proteção do patrimônio histórico e artístico nacional e instituiu o instrumento do tombamento. A abrangência conceitual na abordagem do patrimônio cultural está relacionada com a retomada da própria definição antropológica da cultura como tudo o que caracteriza uma população humana ou como o conjunto de modos de ser, viver, pensar e falar de uma dada formação social. Ou, ainda como todo conhecimento que uma sociedade tem de si mesma, sobre outras sociedades, sobre o meio material em que vive e sobre sua própria existência, inclusive as formas de expressão simbólica desse conhecimento através das ideias, da construção de objetos e das práticas rituais e artísticas.

Segundo Santos (2001), apesar de todas as discussões teóricas conduzidas em âmbito internacional, somente em 1982, a UNESCO conseguiu chegar a um acordo sobre a necessidade de uma definição mais abrangente para a cultura, que passa desde então a ser referência: "conjunto de características distintas, espirituais e materiais, intelectuais e afetivas, que caracterizam uma sociedade ou um grupo social [...] engloba, além das artes e letras, os modos de viver, os direitos fundamentais dos seres humanos, os sistemas de valor, as tradições e as crenças" (UNESCO, 2000 apud SANTOS, 2001).

Quanto à concepção de praça, Robba e Macedo (2003, p. 16) afirmam: “a abrangência do termo gera algumas distorções quanto à terminologia dos espaços urbanos [...] para se designar praça o espaço livre deve ser destinado ao lazer da população e ser público”. Haja vista não só a sua importância recreativa, mas também histórica e cultural que está inserida no processo de construção das primeiras cidades e naturalmente as praças.

Destaca-se que, no Brasil, o termo praça está associado a qualquer espaço verde público, canteiros centrais e bancos. Ressalta-se que, além disso, para se caracterizar como tal, as praças para aceitação da população devem conter, em sua essência, fatos históricos remanescentes à sua edificação, que levem aos usuários e moradores contemporâneos a sua importância cultural e se constituem em espaços coletivos, cuja vivência do lazer e da recreação no cotidiano dos moradores garante o exercício pleno da cidadania. Além disso, é um local público que reflete a história do lugar, com suas correlações, interpretações e representatividades.

Nesse sentido, as praças centrais de Araguaína são espaços físicos, lugares agradáveis e representativos para a cidade com todas as suas representações e emotividades. 
|Lugar e patrimônio cultural: a Praça das Bandeiras na área central da cidade de Araguaína-TO|

|Antônia Márcia Duarte Queiroz|

Elas servem como ponto de partida para a análise espacial, pois contribuem para o resgate do processo de formação da cidade, revelando as relações entre o homem e a natureza na construção da cidade.

\section{CONTEXTO DE FORMAÇÃO DA CIDADE DE ARAGUAÍNA NO NORTE DO TOCANTINS}

De acordo com Morais (2014), a compreensão de Araguaína, sob a perspectiva das cidades médias, nos remete à necessidade de uma análise dos processos socioeconômicos espaciais, pois tal localidade se destaca regionalmente como centro prestador de serviços, comércio, lazer, centro de estudos superiores e médico-hospitalares e outros serviços que atendem ao mercado consumidor de seu entorno imediato e de cidades localizadas em um raio de distância que ultrapassa a região Norte do Tocantins, onde geograficamente está localizada.

Para Morais (2014), o processo de estruturação de Araguaína, dentro da rede urbana do Norte do Estado do Tocantins, está pautado na formação socioeconômica da região em que se insere. Assim, o entendimento do método de dinamização da cidade de Araguaína remete à necessidade de levar em consideração as políticas públicas de planejamento, como aspecto fundamental para seu desenvolvimento urbano e regional.

Faz-se importante destacar que algumas dinâmicas se estabeleceram no processo de consolidação econômica e intensificação da urbanização do Estado do Tocantins e na constituição da economia regional da cidade de Araguaína, com destaque para a participação e a dinamicidade de várias empresas ligadas ao setor agropecuário.

Reflexo de tudo isso se percebe pelas ruas da cidade por onde circula um fluxo muito grande de pessoas que dividem os espaços com a frota local de veículos, associado a outros tantos oriundos das localidades que convergem para Araguaína e se utilizam do espaço urbano da cidade para suprir suas necessidades, caso específico da Avenida Cônego João Lima, que, em certos dias do mês, com a movimentação intensa de veículos e pessoas, dificulta o tráfego ao longo de seu trajeto, trazendo para Araguaína os mesmos problemas encontrados em outros centros urbanos maiores do país. Sua função como prestadora de serviços educacionais de nível superior e, especificamente, de serviços ligados à área médico-hospitalar extrapola as fronteiras estaduais. 


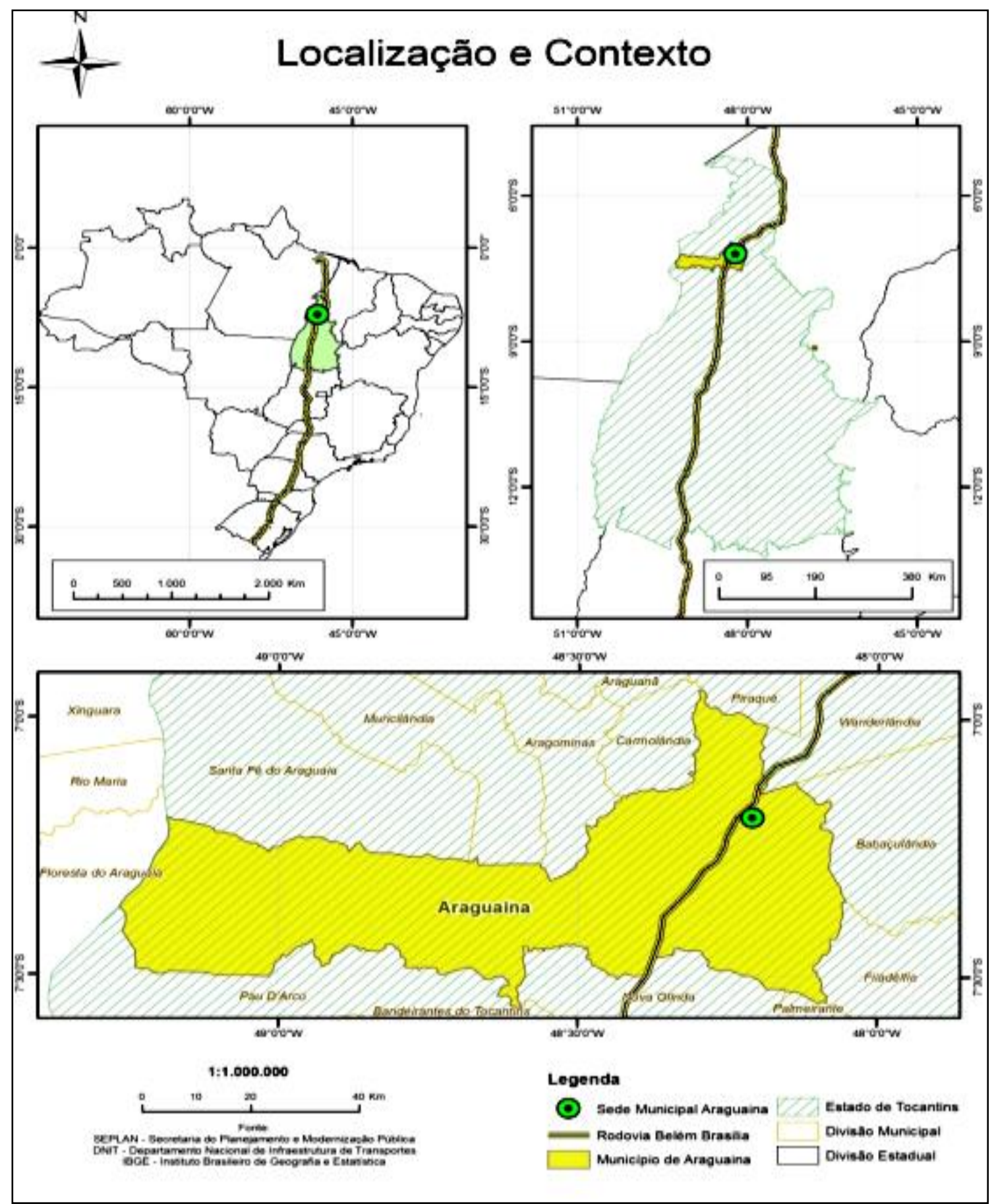

Mapa 1 - Localização da cidade de Araguaína

Fonte: MORAIS, I. A., 2014.

Araguaína apresenta dinâmicas diferenciadas das demais cidades da região, fazendo com que se configure como cidade-polo de uma grande região e, também, se apresenta como uma cidade média no contexto regional.

Correia (2015) argumenta que um dos fortes elementos que se refletem na economia, pela construção da rodovia BR-153, é o movimento de mercadorias, pois as principais vias de circulação do município passaram a se conectar com as rodovias. Desse 
modo, esses eixos de circulação e, portanto, de ligação regional passaram a atuar para além da função eminentemente urbana.

Para Correa (2001), a formação espacial reside no fato de se explicitar teoricamente que uma sociedade só se torna concreta através de seu espaço, do espaço que ela produz, por outro lado, o espaço é inteligível através da sociedade. "É considerada como um metaconceito, um paradigma, que contém e está contida nos conceitos-chave de natureza operatória, de paisagem, de região, espaço, lugar e território" (CORRÊA, 2001, p. 26-27).

Portanto, o espaço da praça pode servir para amenizar os impactos urbanos, estabelecendo características diferentes do ambiente da cidade, preservando a identidade e as referências que a tornaram única.

\section{A PRAÇA NO CENTRO URBANO: marco de influência na construção das relações sociais da cidade}

As praças centrais das cidades fazem parte da sua formação urbana e do seu contexto de estruturação histórico, econômico e cultural.

De acordo com Gonçalves (2003), usamos também a noção de patrimônios culturais, arquitetônicos, históricos, artísticos, etnográficos, ecológicos, genéticos e intangíveis, de recente formulação no Brasil que insere novas categorias, tais como lugares, festas, religiões, dentre outros. Parece não haver limite para o processo de qualificação dessa palavra.

Abreu (2003) adverte que é preciso, ainda, sublinhar a dimensão que constitui a razão de ser da noção de patrimônio, como herança e legado que se transmite a novas gerações, a dimensão de vida.

De acordo com Sant'Anna (2003), novas e instigantes questões serão colocadas à prática patrimonial tradicional. De início, uma atenção maior ao uso e à prática dos espaços protegidos, mas também, uma ideia de identidade e uma noção de autenticidade mais complexa e dinâmica.

Para Oliven (2003), o termo patrimônio refere-se a algo que herdamos e que, por conseguinte, deve ser protegido.

Calvino (2006) aborda em seu livro As cidades Invisiveis, nomenclaturas femininas para expor suas impressões e representações sobre as cidades e as praças:

As cidades e a memória: [...] Diomira: Cidade com sessenta cúpulas de prata, estátuas de bronze de todos os deuses; Isioda: Na praça, há o murinho dos 
|Antônia Márcia Duarte Queiroz|

velhos que vêem a juventude passar, ele está sentado ao lado deles. Os desejos agora são recordações; [...] Zaíra: A cidade é feita das relações entre as medidas de seu espaço e os acontecimentos do passado [...] Zora: Cidade que quem viu uma vez nunca mais consegue esquecer. [...] Maurília: a praça idêntica mas com uma galinha no lugar da estação de ônibus, o coreto no lugar da fábrica de explosivos (CALVINO, 2006, p. 11).

Calvino (2006) consegue transpor para o seu texto sentimento e pertencimento do lugar das praças nas cidades, suas próprias simbologias, memórias e significados que as tornam únicas.

No caso da Praça das Bandeiras na cidade de Araguaína, as transformações humanas se impõem alterando o espaço material, obrigando o imaterial da subjetividade assumir adaptações constantes na ocupação e utilização desses espaços urbanos.
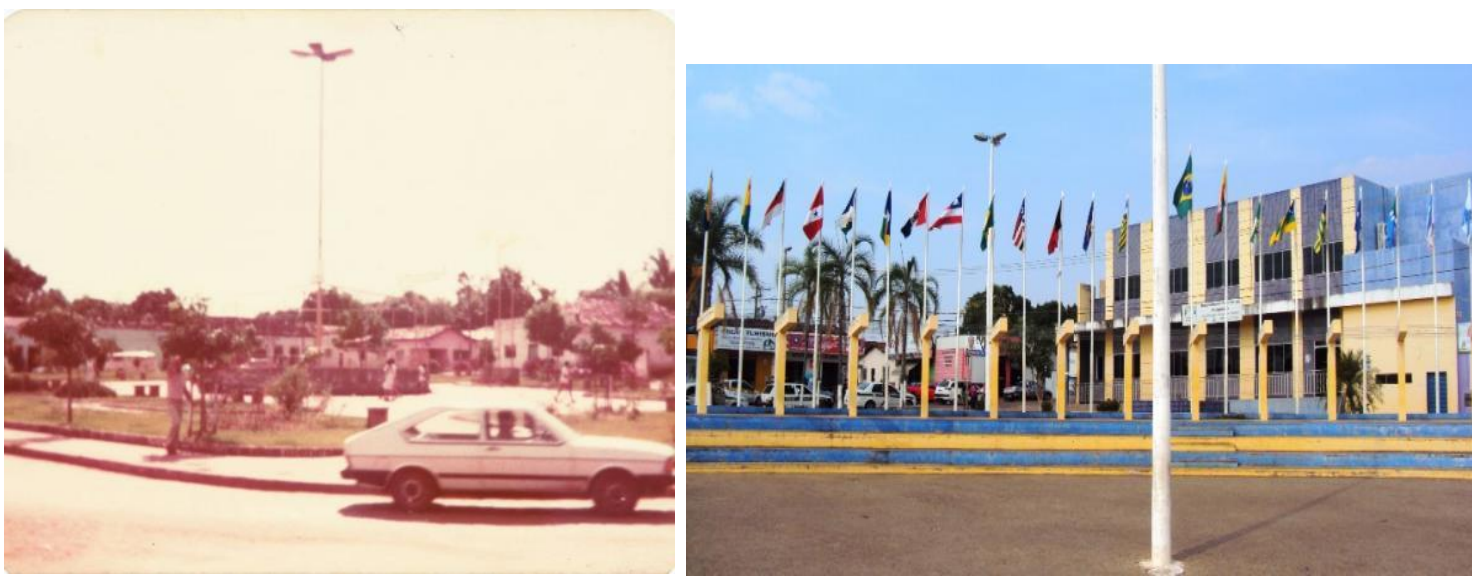

Figura 01 - Praça das Bandeiras (Araguaína-1989 e 2018)

Fonte: <https://www.google.com.br/search?q=ARAGUAINA+PRA\%C3\%87A+DAS+>. Acesso em: set. de 2018.

A Figura 01 mostra a Praça das Bandeiras na área central de Araguaína, muito importante para a formação urbana da cidade. Podemos observar, pelas duas imagens, que, ao longo do tempo, aconteceram muitas transformações. As praças, na condição de patrimônios, identificam-se nas palavras de Drummond (2007), que apontam que o urbano é a capital do patrimônio e se distingue em patrimônio cultural construído pelos humanos e o natural construído maciçamente por processos supra-humanos ou extra-humanos.

$\mathrm{Na}$ memória de alguns antigos moradores, a Praça das Bandeiras representava local de encontro dos membros da comunidade, havia várias árvores e uma maior, específica, onde as pessoas se reuniam para vender e comprar produtos. A praça atual perdeu essa função, mas adquiriu outros papéis inerentes à centralidade urbana comercial e de circulação de pessoas. Atualmente, estão instalados um restaurante popular, um ponto central de ônibus coletivo, lojas comerciais, lanchonetes, sorveteria e ponto de táxi. 
Sydow (2017) destaca a importância da Praça das Bandeiras como lugar central urbano e patrimônio cultural na medida em que mostra sua utilização pela comunidade local por meio da realização do $1^{\circ}$ Festival Gastronômico de Araguaína, além de outras atividades como exposições e festival com apresentações teatrais e sanfoneiros. A praça está identificada por essa autora entre as cinco utilizadas como espaços de lazer públicos da cidade de Araguaína.

A partir desses pressupostos a Praça das Bandeiras serviu como objeto de investigação por meio do Projeto de Extensão "Nós Propomos” (UFT/IGOT e SEDUC). E, intermédio dos dados resultantes da proposta de intervenção urbana "Praça nossa de todo dia”, realizada pelo colégio Estadual Guilherme Dourado, sob minha coordenação (UFT), a participação da SEDUC por meio da professora Luciana Barbosa, professor Mariano Soares da Costa, a professora Maria das Neves Sousa Lima e estudantes do Ensino Médio. O intuito do Projeto Nós Propomos por meio da educação geográfica é propor sugestões para o melhor aproveitamento e a revitalização dos espaços urbanos.

O estudo se torna relevante à medida que a praça faz parte do entorno desse colégio e possui localização central na cidade de Araguaína.

Inicialmente, com o objetivo de diagnosticar os usos do espaço da Praça das Bandeiras, a equipe realizou trabalho de campo para identificar os problemas urbanos locais e uma consulta à comunidade para, especificamente, identificar os problemas de estrutura física e segurança e a utilização da comunidade para o lazer e cultura.

O diagnóstico realizado pela equipe em trabalho de campo identificou que a comunidade e as famílias estão deixando de utilizar esse espaço devido à insegurança e ao desconforto, pois há mau cheiro, sujeira e falta de estrutura física adequada aos visitantes. São visíveis os problemas estruturais do local observados in loco: Lixo a céu aberto, provocando mau cheiro e atraindo baratas e ratos; estrutura física precária; pouca arborização, tornando o lugar ainda mais quente que o habitual; água parada, o que favorece o desenvolvimento de mosquitos transmissores de doenças; aumento no número de casos de violência e uso de drogas; e grande número de moradores de rua fazendo dali sua moradia. 


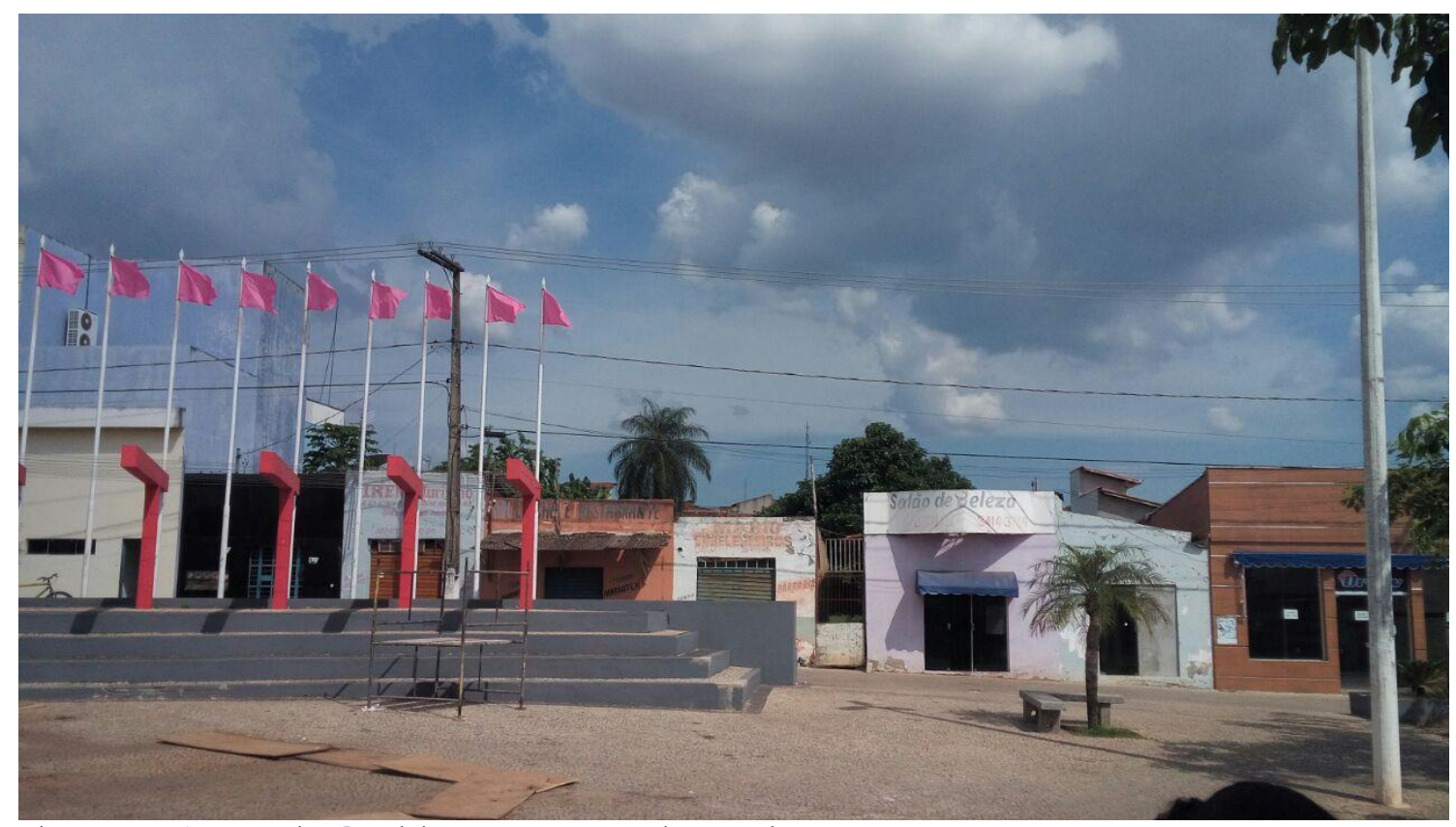

Figura 02 - A Praça das Bandeiras na percepção dos estudantes

Fonte: Arquivo do Colégio Estadual Guilherme Dourado (Araguaína, 2018).

A Figura 02 mostra a situação precária da Praça das Bandeiras. Sydow (2017) alertou sobre a qualidade ruim dessa praça como espaço de lazer e sem condições de uso à medida que apresenta falta de estrutura adequada. Em relação à segurança, há ausência de policiamento e as condições de iluminação são precárias. A autora supracitada detectou também que a praça tem pouca cobertura vegetal, o que dificulta a permanência nesse espaço, contradizendo o que está posto no Plano Diretor (Lei 2.424) do município, que afirma, na SEÇÃO III, Art. 11, VII, que a organização de um espaço urbano de qualidade será efetivada por meio de, entre outros, instalação de jardins.

Além disso, os poucos bancos de descanso encontrados estão em más condições de uso, as superfícies são irregulares, o que dificulta o deslocamento, principalmente, de pessoas com deficiências físicas e idosas, faltas ainda de local de descarte do lixo, que exala forte mau cheiro.

Contudo, apesar das condições precárias das praças de Araguaína, Sydow (2017) afirma que é o segundo espaço mais frequentado pelos moradores, sua avaliação foi considerada como sendo um bom espaço pela maioria $(87,6 \%)$ das pessoas que as frequentam e as condições foram avaliadas como ótimas e ruins por apenas $6,2 \%$ das pessoas. As pessoas vão às praças tanto com a família como com os amigos, o que indica que, ao compartilharem um espaço público de lazer com a família, preferem as praças ao parque. 
|Lugar e patrimônio cultural: a Praça das Bandeiras na área central da cidade de Araguaína-TO|

|Antônia Márcia Duarte Queiroz|

Espaços de lazer típicos e muitas vezes único das pequenas cidades, as praças revelam toda a simbologia e a centralidade da vida urbana interiorana, guardando, em si, muitas memórias, talvez, por isso, sejam um ambiente propício para ser desfrutado com a família.

Pelos argumentos supracitados, torna-se relevante apresentar as contribuições da comunidade escolar do Colégio Guilherme Dourado e acadêmica (UFT) na tomada de consciência sobre a importância da praça urbana como patrimônio cultural local e regional, além de promover ações junto à comunidade local e sugerir ações para o poder público no sentido de revitalização da Praça das Bandeiras em Araguaína.

Quadro 1 - Ações promovidas junto à comunidade escolar do Colégio Guilherme Dourado

\begin{tabular}{|c|c|}
\hline $\begin{array}{lllllr}\text { REUNIÃO COM } & \text { OS } & \text { ALUNOS } & \text { DAS } \\
\text { TURMAS DAS } 1^{\mathrm{a}} & \text { E } & 2^{\mathrm{a}} & \text { SÉRIES } & \text { DO } \\
\text { ENSINO MÉDIO } & & & & \\
\end{array}$ & $\begin{array}{l}\text { Reunir todas as turmas do Ensino Médio do Colégio } \\
\text { Estadual Guilherme Dourado com a finalidade de } \\
\text { definir as ações. }\end{array}$ \\
\hline $\begin{array}{l}\text { DISCUSSÃO E DEFINIÇÃO DAS AÇÕES } \\
\text { A SEREM ADOTADAS NO PROJETO } \\
\text { DE REVITALIZAÇÃO DA PRAÇA DAS } \\
\text { BANDEIRAS }\end{array}$ & $\begin{array}{l}\text { Reunir a Equipe Gestora do Colégio, professores e } \\
\text { representantes das turmas, para o planejamento de } \\
\text { ações de conscientização a serem desenvolvidas pelo } \\
\text { Colégio. }\end{array}$ \\
\hline $\begin{array}{l}\text { ELABORAÇÃO E CONFECÇÃO DOS } \\
\text { PANFLETOS DE CONSCIENTIZAÇÃO }\end{array}$ & $\begin{array}{l}\text { Elaborar os panfletos de sensibilização para a } \\
\text { conservação do ambiente para posteriormente distribuir } \\
\text { à comunidade. (trabalho feito pelos alunos das turmas, } \\
\text { orientado pelos professores). }\end{array}$ \\
\hline REALIZAÇÃO DE PALESTRAS & $\begin{array}{l}\text { Proferir palestras de conscientização sobre o uso e a } \\
\text { manutenção dos espaços da cidade. }\end{array}$ \\
\hline $\begin{array}{l}\text { CAMPANHA DE PARCERIA COM O } \\
\text { COMÉRCIO LOCAL }\end{array}$ & $\begin{array}{l}\text { Visitar o comércio do entorno da praça com a } \\
\text { finalidade de firmar parceria no combate à degradação e } \\
\text { à violência da Praça das Bandeiras (trabalho } \\
\text { desenvolvido pelos alunos das turmas, orientados pelos } \\
\text { professores). }\end{array}$ \\
\hline $\begin{array}{l}\text { CAMPANHA DE CONSCIENTIZAÇÃO } \\
\text { DA CONSERVAÇÃO E LIMPEZA DA } \\
\text { PRAÇA }\end{array}$ & $\begin{array}{l}\text { Realizar periodicamente campanha e distribuição de } \\
\text { panfletos para a comunidade (intervenção dos alunos } \\
\text { na conscientização da limpeza e conservação). }\end{array}$ \\
\hline DIVULGAÇÃO DAS ATIVIDADES & $\begin{array}{l}\text { Alimentar o blog do Colégio com documentos, } \\
\text { depoimentos, entrevistas, fotos e outros, das atividades } \\
\text { desenvolvidas ao longo da realização deste projeto. }\end{array}$ \\
\hline AVALIAÇÃO PERIÓDICA & $\begin{array}{l}\text { Reunir a equipe gestora, professores e alunos, munidos } \\
\text { de evidências dos trabalhos realizados para análise e } \\
\text { intervenção das ações, ampliando, excluindo ou } \\
\text { adequando novas propostas, quando se fizer necessário. }\end{array}$ \\
\hline
\end{tabular}

Fonte: Resultados do Projeto Nós Propomos, 2017 (UFT/Araguaína). 
Quadro 02 - Propostas sugeridas pela comunidade escolar do Colégio Guilherme Dourado ao poder público local

\begin{tabular}{|c|c|}
\hline LIXO & $\begin{array}{l}\text { Instalar coletores seletivos de lixo (parceria com a } \\
\text { Cooperativa dos Catadores de materiais recicláveis de } \\
\text { Araguaína); }\end{array}$ \\
\hline ESTRUTURA FÍSICA PRECÁRIA & $\begin{array}{l}\text { Restaurar a fonte luminosa, repor os blocos do piso, pintura } \\
\text { de toda estrutura física e manutenção da iluminação e dos } \\
\text { bancos. }\end{array}$ \\
\hline ARBORIZAÇÃO & $\begin{array}{l}\text { Construir jardins com pneus e outros materiais recicláveis, } \\
\text { manutenção dos canteiros (parceria com a Associação dos } \\
\text { Artesãos do Município); }\end{array}$ \\
\hline ÁGUA PARADA & $\begin{array}{l}\text { Uma vez sendo coletado o lixo diariamente e restaurada a } \\
\text { fonte luminosa, será eliminada a possibilidade de } \\
\text { proliferação de mosquitos e hospedeiros transmissores de } \\
\text { doenças. }\end{array}$ \\
\hline VIOLÊNCIA E USO DE DROGAS & $\begin{array}{l}\text { Instalar um posto policial permanente na Praça das } \\
\text { Bandeiras para inibir a ação dos bandidos e usuários de } \\
\text { drogas, bem como a permanência de um vigilante para } \\
\text { auxiliar no combate ao vandalismo; }\end{array}$ \\
\hline $\begin{array}{l}\text { GRANDE NÚMERO } \\
\text { MORADORES DE RUA }\end{array}$ & $\begin{array}{l}\text { Recolhimento dos moradores de rua para posto domiciliar e } \\
\text { assistência à saúde física e mental (Secretaria Municipal da } \\
\text { Assistência Social). }\end{array}$ \\
\hline
\end{tabular}

Fonte: Resultados do Projeto Nós Propomos, 2017 (UFT/Araguaína).

As ações e propostas sugeridas refletem a importância da praça para os estudantes e revelam a preocupação em torná-la mais agradável para todos da comunidade local, como um patrimônio cultural e simbólico de pertencimento na área central da cidade de Araguaína.

A praça é um local importante nas áreas urbanas que serve como ponto de partida também para a análise espacial que possibilite o resgate do processo de formação da cidade, revelando as relações entre o homem e a natureza na sua construção.

O espaço urbano se modifica e a praça acompanha essas transformações, que representam uma nova configuração, em que antigas características desapareceram em função das adaptações de um novo cenário da praça, seja em âmbito social, econômico, paisagístico, bem como nas concepções ideológicas de lugar.

Santos (2002) considera que as cidades se distinguem uma das outras por fixos e fluxos e mudá-los é mudar sua própria significação para os próprios moradores, pois a cidade é um fixo enorme e tem fixos econômicos, sociais e culturais.

Assim pode-se afirmar que a praça tem características próprias, onde as relações sociais se desenvolvem em meio ao espaço urbano, que é dinâmico, em uma cidade que está sempre mudando, sempre exercendo novas funções.

Sendo assim, é possível afirmar que as praças da cidade de Araguaína se constituem como lugares de patrimônio cultural à medida que nesses espaços se estabelecem relações 
|Lugar e patrimônio cultural: a Praça das Bandeiras na área central da cidade de Araguaína-TO|

|Antônia Márcia Duarte Queiroz|

políticas, sociais, culturais e econômicas. Portanto, são espaços dinâmicos que têm memória coletiva simbólica e de pertencimento.

\section{CONSIDERAÇÕES FINAIS}

As praças, além de conservarem o histórico local de servir para amenizar os impactos urbanos na área central das cidades, principalmente, naquelas consideradas áreas verdes, estabelecem ainda características diferentes do ambiente da cidade. Preservam, além da identidade e da cultura local, as referências e características que a tornam única, por apresentar comerciantes ambulantes, bancos para assento, posto policial, pontos de táxi, árvores, fontes e brinquedos, entre outras características.

O lugar é constituído, conforme Tuan, como um "espírito", como uma "personalidade". Se o lugar fizer algum "sentido" para as pessoas, certamente será manifestado pela apreciação visual ou estética, como também pelos sentidos desenvolvidos pela relação homem x lugar, seja ele topofóbico ou topofílico.

Enfim, as praças, em especial, as praças centrais das cidades são lugares a serem conservados e recuperados quando necessário, são lugares de realizações culturais, folclóricas e festivas, representam a história do povo do lugar. Ou seja, as praças centrais da cidade podem ser consideradas como um espírito, como uma personalidade, pois é o lugar da cidade que faz sentido para as pessoas, pela apreciação visual, pelos sentidos que relacionam homem x lugar, tanto para os moradores locais, quanto para os "de fora", os diversos turistas que passam pela cidade.

Promover a reflexão por intermédio de projetos de extensão sob a interação entre a universidade e a comunidade local, com base na identificação de problemas urbanos e na formulação de propostas fundamentadas, criativas e viáveis de resoluções para esses problemas serve como inspiração ao pensamento geográfico no sentido de produzir novas afirmações teóricas e conceituais.

Nessa perspectiva, pode-se direcionar a cidade a se preocupar com a praça na área central da cidade de Araguaína como patrimônio cultural intangível, pois o lugar, os aspectos históricos, sociais, econômicos e culturais sempre estão em correlação com perspectivas para o futuro. Nela, estão representados os desejos, as recordações, a relação entre as medidas de seu espaço e os acontecimentos do passado de quem viu uma vez e que nunca mais consegue esquecer aquelas imagens extraordinárias nas suas recordações 
imóveis e imutáveis que facilitam a memorização, sem conseguir se desfazer e/ou desaparecer.

Assim cabe às praças urbanas ser alvo de constantes reflexões geográficas em virtude das suas transformações, que produzem elementos diversos que interagem, produzindo as complexidades da realidade local.

\section{REFERÊNCIAS}

ABREU, Regina. A emergência do patrimônio genético e a nova configuração do campo do patrimônio. In: ABREU, Regina; CHAGAS, Mário (Org.). Memória e patrimônio: ensaios contemporâneos. Rio de Janeiro: DP\&A, 2003.

ALVES, Lidiane Aparecida. Os processos socioespaciais da zona periférica do centro: um estudo da área central de Uberlândia (MG). 2011. Dissertação (Mestrado em Geografia) - Instituto de Geografia, Universidade Federal de Uberlândia, Uberlândia-MG, 2011.

ARCHELA, Rosely Sampaio [et al.]. O lugar dos mapas mentais na representação do lugar. Geografia (Londrina), v. 13, n. 1, jan./jun. 2004. Disponível em: $<$ http://www.uel.br/revistas/uel/index.php/geografia/article/view/6794>. Acesso em: 20 out. 2018.

CALVINO, Italo. As cidades invisíveis. São Paulo: Companhia das letras; 2006.

CORRÊA, Roberto Lobato. O Espaço Urbano. 3. ed. São Paulo: Ática, 1995. (Série Princípios, n. 174).

CORRÊA, Roberto Lobato. Espaço: um conceito-chave da Geografia. In. CASTRO, Iná Elias de [et al.] (Org.) Geografia: conceitos e temas. 3. ed. Rio de Janeiro: Bertrand Brasil, 2001.

CORREIA, Luiz Soares. A influência da BR-153 no crescimento e desenvolvimento econômico de Araguaína. 2015. Dissertação (Mestrado em Transportes) - Universidade de Brasília, Brasília, 2015.

DRUMMOND, José Augusto. Patrimônios natural e cultural: endereços distintos nos espaços urbanos, rurais e selvagens. In: LUCHIARI, Maria Tereza Paes [et al.] (Org.). Patrimônio, natureza e cultura. Campinas: Papirus, 2007. p. 103-114.

GONÇALVES, José Reginaldo Santos. O patrimônio como categoria de pensamento. In: In: ABREU, Regina; CHAGAS, Mário (Org.). Memória e patrimônio: ensaios contemporâneos. Rio de Janeiro: DP\&A, 2003. p. 21-29

LAUANDE JUNIOR, Francisco de Assis. Brasília: a praça dos três poderes. 2008. Dissertação (Mestrado em Arquitetura e Urbanismo) - Universidade de Brasília, Brasília, 2008. 
LOPES, Michelly de Lourdes. O comércio varejista em Uberlândia (MG) e sua atuação como agente modificador do espaço urbano: as estratégias da rede Bretas de supermercados. 2012. Dissertação (Mestrado em Geografia) - Universidade Federal de Uberlândia, Uberlândia-MG, 2012.

MORAIS, Itamar Araújo. Araguaína (TO): enquanto Cidade Média no contexto regional. 2014. Dissertação (Mestrado em Geografia) - Instituto de Ciências Humanas, Departamento de Geografia, Universidade de Brasília, 2014.

OLIVEN, Ruben George. Patrimônio intangível: considerações iniciais. In: ABREU, Regina; CHAGAS, Mário (Org.). Memória e patrimônio: ensaios contemporâneos. Rio de Janeiro: DP\&A, 2003. p. 77-80.

SANT'ANNA, Márcia. A face imaterial do patrimônio cultural: os novos instrumentos de reconhecimento e valorização. In: ABREU, Regina; CHAGAS, Mário (Org.). Memória e patrimônio: ensaios contemporâneos. Rio de Janeiro: DP\&A, 2003. p. 46-55.

SANTOS, Cecília Rodrigues dos. Novas fronteiras e novos pactos para o Patrimônio Cultural. São Paulo em Perspectiva, v. 15, n. 2, p. 43-48, abr./jun. 2001. Disponível em: < http://dx.doi.org/10.1590/S0102-88392001000200007> . Acesso em: 20 out. 2018.

SANTOS, Milton. A natureza do espaço: técnica e tempo, razão e emoção. 3. ed. São Paulo: Hucitec, 2002.

SYDOW, Elisabeth. Os espaços e equipamentos públicos de lazer da cidade de Araguaína (TO) sob a ótica de seus moradores. 2017. Tese (Doutorado) - Escola de Educação Física, Fisioterapia e Terapia Ocupacional, Universidade Federal de Minas Gerais, Belo Horizonte, 2017.

VAZ, Domingos. O urbano e o território: notas sobre algumas questões emergentes. In: BALSA, Casimiro (Org.). Relações Sociais de Espaço - Homenagem a Jean Remy. Lisboa: Edições Colibri/CEOS, 2006. p. 219-230.

ROBBA, Fábio; MACEDO, Silvio Soares. Praças brasileiras. São Paulo: EDUSP, 2003.

TUAN, Y Fu. Espaço e lugar: a perspectiva da experiência. Tradução Lívia de Oliveira. São Paulo: DIFEL, 1983. 